\title{
Initiating Functional Vocabulary Learning for Mental Retardation Students with Educational Technology Approach
}

\author{
Ai-Chiao Ku, Shu-Hsuan Chang, and Li-Chih Yu
}

\begin{abstract}
This study developed functional vocabulary learning system for mental retardation students to assist three moderate ones enrolled in special education classes of vocational schools, and discusses the learning effect of the within and extra fading strategies. And the alternative treatment design of the single subject experiment design was adopted to evaluate the effectiveness of the learning system. The teaching strategy adopted photos of physical goods as cues combined with the fading strategy within a stimulus-control process. After experiment, this study has the preliminary result: Stimulus fading strategies can assist functional vocabulary learning in moderate mental retardation students enrolled in special education classes of vocational schools; learning achievement with the extra fading strategy exceeded that with the within fading strategy.
\end{abstract}

Index Terms-Word recognition, pedagogical agent, special education, vocational education.

\section{INTRODUCTION}

The aim of special education is to help specific disabilities students to turn into independent and adapt to society. Functional skills and reading have been deemed the most important things to facilitate living and working abilities [1], [2]. Moreover, some studies indicated that moderate mental retardation students are able to enhance their work skills and living abilities through functional vocabulary learning [3], [4]. Presently, many studies have demonstrated the benefits of using computers to help retarded students recognize words [5]. Dorry and Zeaman [6], [7] first proposed fading strategies which stimulate learners by transferring their attention from pictures to words, including manipulating the outer features of prompt stimuli (such as color, shape, size, brightness, distance and location), and making those stimuli fade so that prompt stimulus/pictures are transferred to training stimulus/words [8]. There are two different fading strategies, within stimulus fading and extra stimulus fading. The former one is indentified the target word on the picture, and the pictures gradually fade out to transfer learner attention from the pictures to the target words for students learning the target words at every level (as shown in Fig. 1).

Manuscript received August 16, 2013; revised November 26, 2013

$\mathrm{Ai}-\mathrm{Chiao} \mathrm{Ku}$ is with the Industrial Education of Postgraduate studies in Department of Industrial Education and Technology, National Changhua University of Education, Taiwan (e-mail: g1h2c3tw@ yahoo.com.tw).

Shu-Hsuan Chang is with Department of Industrial Education and Technology, National Changhua University of Education, Taiwan (e-mail: shc@cc.ncue.edu.tw).

Li-Chih Yu is with the Department of Management Information System, National Chengchi University, Taiwan (e-mail: lazymen306@gmail.com).
The other is the extra stimulus fading strategy, which involves placing target words beside the pictures, and the pictures gradually fading out for students learn the target words at every level (as shown in Fig. 2). Stimulus fading guided computer-assisted systems help moderate mental retardation students enrich word-recognition, and the effectiveness of within and extra stimulus fading strategies on mentally retarded students, such as shortening learning hours and decreasing error rate, required further discussion. Specifically, through professional courses in special classes, these schools hoped that students could obtain professional licenses and successfully enter the job market. Although most students were mild mental retardation, few of them were moderate ones and thus were considered to function better on word recognition, individual differences among students were significant [9]. An enormous teaching challenge is appealed in special classes of vocational senior high school. Hence, it is essential to find an effective picture-fading technique for students' word learning. This study attempted to develop the Word Recognition Learning System with Fading Strategies, a web-based platform, to help moderate mental retardation students learn functional words for skill test in special classes of vocational senior high schools.

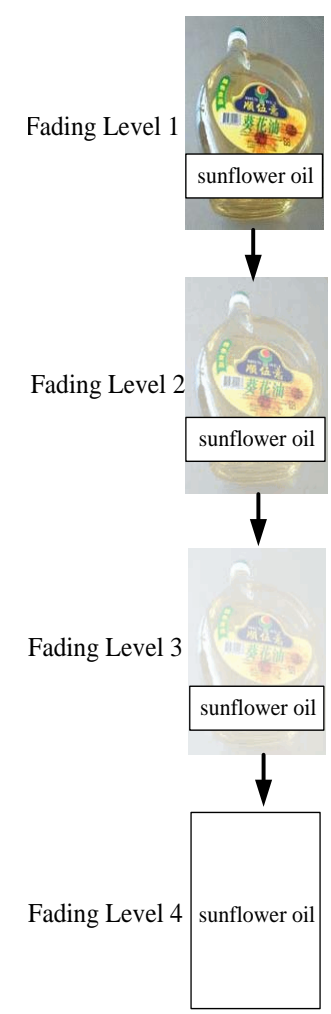

Fig. 1. Four levels of within stimulus fading. 


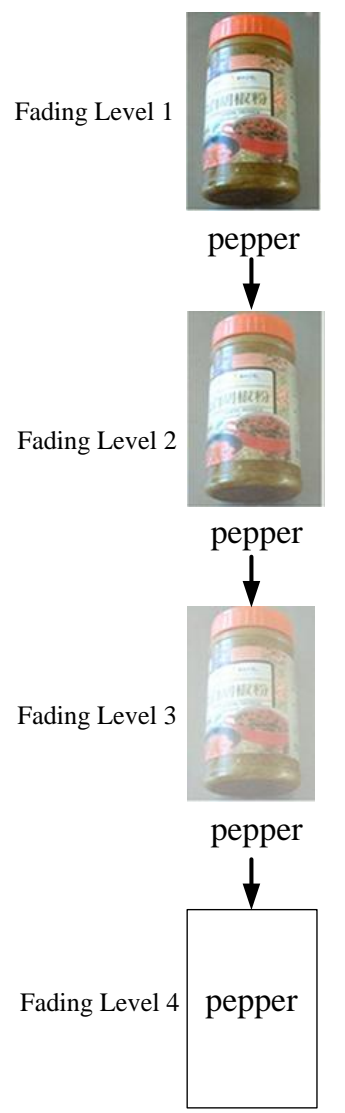

Fig. 2. Four levels of extra stimulus fading.

\section{SYSTEM AND EXPERIMENT DESIGN}

This study created an online learning system regarding the Client-Server model, the Web server contained learning materials, the pedagogical agent's design, and comprehensive assessments. The teaching materials presented the cue cards and target words via animation. The teaching materials presented the cue cards and target words via animation. The IBM via Voice program was applied to the Chinese voice of the pedagogical agent, which performed different feedback to attract learners' attention as shown in Fig. 3. On the other hand, learning materials databases, learner profiles, and learning achievement were contained in the Database Server.

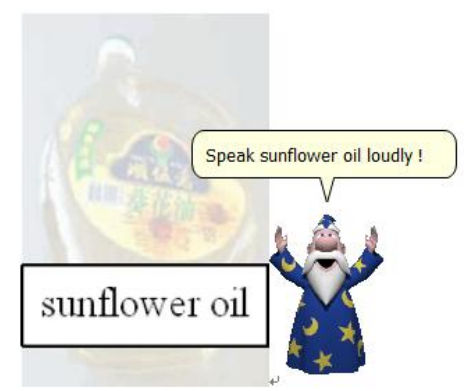

Fig. 3. Introduction of the pedagogical agent.

And this study adopted Alternating Treatment Design (ATD), a single-subject experimental design, which compares the learning achievement of single participant in two or above intervention [10]. Table I shows the demographic information of the three mental retardation students. Participants' intelligence quotient (IQ) from Wechsler Intelligence Scale for Children-III was employed. The independent variables of experiment are the within and extra stimulus fading strategies, which are conducted with teaching websites functional vocabulary from the Chinese Cuisine Cookery and Western Culinary textbook, which forms the teaching materials, such as ingredients and cooking terms with the stroke and word number to control the difficulty of the materials. The dependent variables include student learning achievement, learning efficiency and learning maintenance.

TABLE I: PARTICIPANTS AND DEMOGRAPHIC INFORMATION

\begin{tabular}{ccccl}
\hline \hline Subject & Sex & Age & WISC-III(IQ) & \multicolumn{1}{c}{ Recognition Ability } \\
$\begin{array}{c}\text { Subject } \\
\text { A }\end{array}$ & female & 18 & 52 & $\begin{array}{l}\text { Only know simple words and } \\
\text { sometimes have mistakes in } \\
\text { writing her own name }\end{array}$ \\
\hline $\begin{array}{c}\text { Subject } \\
\text { B }\end{array}$ & male & 19 & 42 & $\begin{array}{l}\text { Know few words about } \\
\text { common used words, such as } \\
\text { toilet, dangerous and so on }\end{array}$ \\
$\begin{array}{c}\text { Subject } \\
\text { C }\end{array}$ & male & 18 & 48 & $\begin{array}{l}\text { Only know some simple } \\
\text { words, such as boy, girl, toilet } \\
\text { and so on }\end{array}$ \\
\hline \hline
\end{tabular}

\section{RESULTS}

Fig. 4 (a)-Fig. 4 (c) revealed the graphs of subject A's learning achievement during three phases with six sets of words learning under two stimulus fading strategies. After the fifth session and maintenance phase, the accuracy rate of subject A reached $80 \%$ three times consecutively. Therefore, Subject A displayed no significant difference in learning achievement under the two strategies. Fig. 5 (a)-Fig. 5 (c) showed the graphs of learning achievement for subject B. Since subject B was brain damaged, his learning time was three sessions longer than other participants. Notably, subject $B$ achieved better learning results under the extra stimulus fading strategy. However, during the maintenance phase, the accuracy rate of subject $\mathrm{B}$ in answering target words decreased obviously no matter which strategy used. Fig. 6 (a)-Fig. 6 (c) showed the graphs of learning achievement of subject C. After the intervention of stimulus fading strategies, subject $\mathrm{C}$ reached the expected goal under the extra fading strategy. However, the performance of subject $\mathrm{C}$ was as decreasing as subject $\mathrm{B}$ during the maintenance phase. Because students with retardation have trouble retaining information in their short-term memory, they have poor process of storing and retaining information for a limited period of time. Moreover, such students have difficulty on retaining information without excessive practice and other memory techniques. Consequently, if students do not review these learned words frequently, they would not be able to keep the words in the long term memory and applied in their daily life [11].

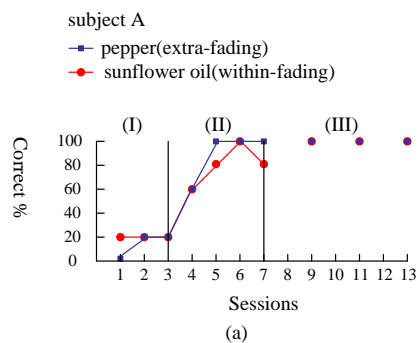

(a) 


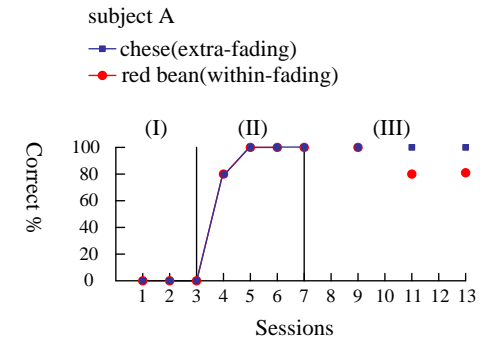

(b)

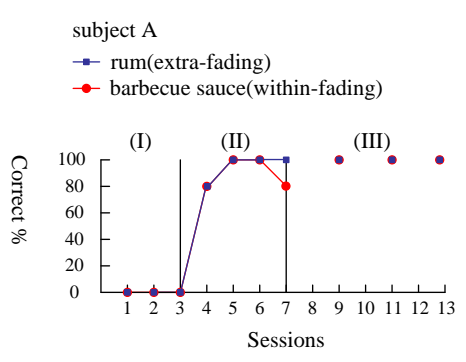

(c)

Fig. 4. Graphs of learning achievement of subject A.

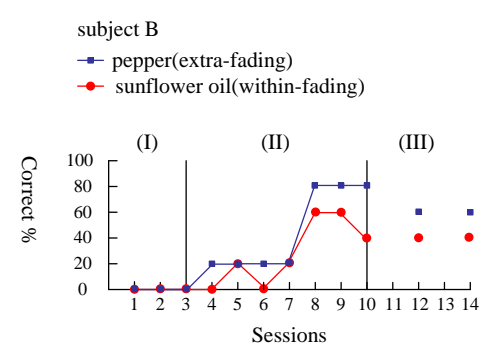

(a)

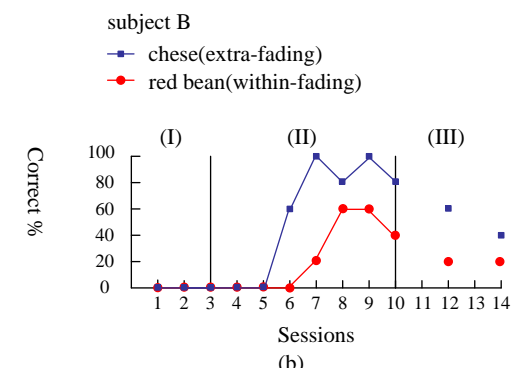

(b)

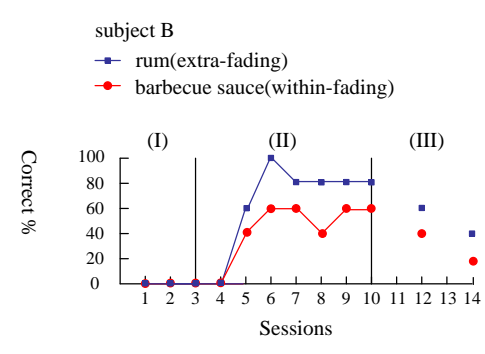

(c)

Fig. 5. Graphs of learning achievement of subject B.

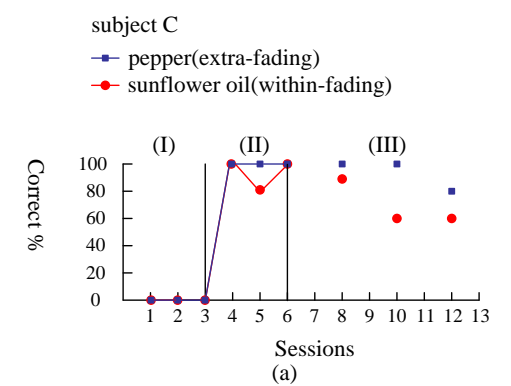

(a)

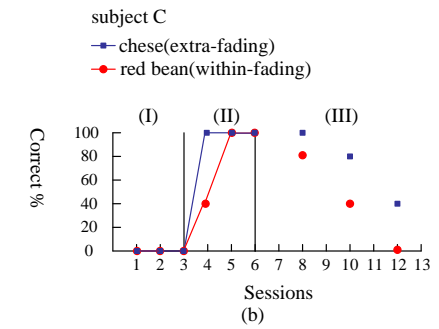

subject C

- rum(extra-fading)

$\bullet$ barbecue sauce(within-fading)

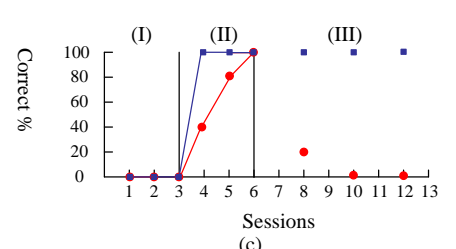

(c)

Fig. 6. Graphs of learning achievement of subject C.

This study recorded subjects' special behaviors in the teaching experiment. According to the diary and observations of special education teachers, all subjects enjoyed learning via computer rather than picture cards. The feedback of the pedagogical agent attempted to attract students' attention, increase their interest, inspire learning motivation and advance their learning effect. In-depth interviews with the moderate mental retardation subjects explored that these students were fond of the pedagogical agent's guidance. While subjects had learned the words, they were frequently bored by the repeated appearance and prompts of the pedagogical agent. Thus, using computer to recognize words may increase students' motivation, maintain their learning desire, and shorten learning hours. Nevertheless, in order to create more meaningful learning, the design of pedagogical agent should provide more interactive with users according to their needs.

\section{DISCUSSION}

The goal of this study was to develop a Word Recognition Learning System with Fading Strategies, to help special classes students of vocational senior high school overcome the difficulty of word recognition, and explore the effects of within and extra stimulus fading strategies. The conclusions were presented as follows. 1) All subjects preferred learning through computer not picture cards. Students' attention, interest, and learning effect were reinforced by the feedback of the pedagogical agent. 2) Both within and extra stimulus fading strategies were able to improve students' word recognition. Subject A had the significant effect on learning achievement. The difference between the two strategies was not obvious. On the other hand, learning achievement of subjects $\mathrm{B}$ and $\mathrm{C}$ were improved only under the extra stimulus fading strategy. However, for the students with moderate retardation should be repeated practice to improve their performance in memory maintenance [12].

\section{REFERENCES}

[1] J. S. Lalli and D. M. Browder, "Comparison of sight word training procedures with validation of the most practical procedure in teaching 
reading for daily living," Research in Developmental Disabilities, vol. 14, no. 2, pp. 107-127, March-April 1993.

[2] L. C. Mechling, D. L. Gast, and J. Langone, "Computer-based video instruction to teach persons with moderate intellectual disabilities to read grocery aisle signs and locate items," The Journal of Special Education, vol. 35, no. 4, pp. 224-240, January 2002.

[3] R. Stromer and H. A. Mackay, "Spelling and emergent picture-printed word relations established with delayed identity matching to complex samples," Journal of Applied Behavior Analysis, vol. 25, no. 4, pp. 893-904, Winter 1992.

[4] M.-C. Chen, T.-F. Wu, Y. L. Lin, Y.-J. Tasi, and H.-C. Chen, "The effect of different representations on reading digital text for students with cognitive disabilities," British Journal of Education Technology, vol. 40, no. 4, pp. 764-770, July 2009.

[5] J. Vedoraa and R. Stromerb, "Computer-based spelling instruction for students with developmental disabilities," Research in Developmental Disabilities, vol. 28, no. 5, pp. 489-505, October-November 2007.

[6] G. W. Dorry and D. Zeaman, "The use of a fading technique in paired-associate reading vocabulary with retardates," Mental Retardation, vol. 11, no. 6, pp. 3-6, December 1973.

[7] G. W. Dorry and D. Zeama, "Teaching a simple reading vocabulary to retarded children: Effectiveness of fading and non-Fading procedure," American Journal of Mental Deficiency, vol. 79, pp. 711-716, 1975.

[8] P. M. Smeets and S. Strefef, "Discrimination training of mirror-image stimuli with a delayed-prompt technique: Some critical dimensions of extra-stimulus prompts," Journal of Experimental Child Psychology, vol. 49, no. 2, pp. 275-299, April 1990.

[9] Vocational Course of Curriculum Guidelines for Special Education Classes in Secondary School, Ministry of Education, Taipei, 2000.

[10] D. H. Barlow and S. C. Hayes, "Alternating treatment design: One strategy for comparing the effects of two treatments in a single subject," Journal of Applied Behavior Analysis, vol. 12, no. 2, pp. 199-210, Summer 1979.

[11] W. L. Heward, Exceptional Children: An Introduction to Special Education, MA: Merrill, 2006.
[12] C. Lee, Learning Disabilities and Assistive Technologies: An Emerging Way to Touch the Future, Amherst, MA: McGowan Publications, 1999

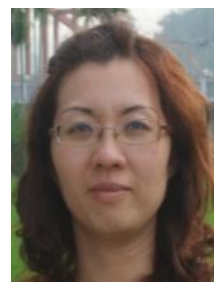

Ai-Chiao Ku has completed her M.S. studies at the Institute of Information and Computer Education, National Taiwan Normal University, Taiwan. Now, she is Ph.D candidate of the Department of Industrial Education and Technology, National Changhua University of Education, Taiwan. And her main research interests include the industrial and vocational education and the use of ICT in education.

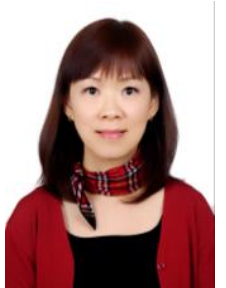

Shu-Hsuan Chang is currently a professor of the Department of Industrial Education and Technology as well as the director of E-Learning Center, National Changhua University of Education (NCUE), Taiwan. She received the B.S. and M.S. degrees in Industrial Engineering from National Chiao-Tung University, Taiwan, and the Ph.D. degree in Department of Industrial Education and Technology from NCUE, Taiwan. Her research interests include engineering and technological education, decision-making science, technology management, innovation management, and photonics.

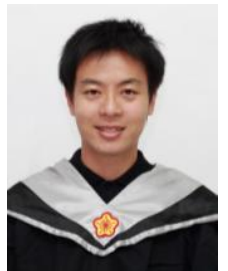

Li-Chih Yu received his M.S. degree from the Department of Management Information System, National Changhua University of Education, Taiwan. $\mathrm{He}$ is Ph.D student at the Department of Managemen Information System, National Chengchi University, Taiwan. His research interests include E-Learning, Business Intelligence, and Entrepreneurship Education 